\title{
Molecular Identification, Species Composition and Distribution Maps of Malaria Vector Species in SelectedCommunities in Benue State, North Central Nigeria.
}

\author{
Aju-Ameh, O.C ${ }^{1}$, Awolola, T.S ${ }^{2}$, Mwansat, G.S ${ }^{1}$ andMafuyai, H.B ${ }^{1}$ \\ ${ }^{I}$ Department of Zoology, Faculty of Natural Sciences, University of Jos, Plateau State, Nigeria \\ ${ }^{2}$ Molecular Entomology and Vector Control Research Laboratory, Public Health Division Nigerian Institute of \\ Medical Research, Lagos, Nigeria
}

\begin{abstract}
An accurate and detailed knowledge of theIdentification,composition and distribution of malaria vectors is needed to guide malaria control programmes.An investigation to accurately identify malaria vectors using standard molecular protocols was carried out in selected rural and urban communities in Benue State, North Central Nigeria where such baseline data was not previously available. Sampling was carried out using Pyrethrum Spray Catch (PSC) from January to December 2015. A total of 1,734 mosquitoes were recorded of which Culex peaked 1,410 (81.31\%), Anopheles 276 (15.92\%),Mansoni 14(0.81\%), Aedes 3(0.17\%) and unidentified accounted for $31(1.79 \%)$. There was a significant difference $(P=0.001)$ between rural and urban communities in species composition at $(P<0.05)$.A Polymerase Chain Reaction $(P C R)$ assay identified two major species within the Anopheles gambiae complex; Anopheles gambiaes.s. and Anopheles arabiensis. Further identification using the Polymerase Chain Reaction-Restriction Fragment Length Polymorphisim (PCR-RFLP) revealed the presence of all three molecular forms (M,S, and $H)$ of Anopheles gambiaes.s.; and for the first time detection of the hybrid form $(H$ form).The distribution maps presented here highlights the existence and location of two members of the Anopheles gambiae complexand three members of the Anopheles gambiaes.s.
\end{abstract}

Keywords: An.gambiae, $M, S \& H$ forms, Distribution map, PCR, PCR-RFLP, North Central, Nigeria

\section{Introduction}

The animals that pose a potent threat to human life presently in Sub-Saharan Africa (SSA) area group of arthropod vectors belonging to the Anopheles gambiae complex.It is a complex comprising of eight sibling species:An.gambiae s. str., An.arabiensis, An. melas, An. merus, An.bwambae,An.quadriannulatus species A, An. quadriannulatus species B, and An.Comorensis ${ }^{[1]}$.As many as three or four specie exist sympatrically in certain regions and at least two occur in malaria -endemic areas ${ }^{[2]}$. Sinka and co-authors ${ }^{[3]}$ asserts that the continent of Africa experiences the bulk of the global malaria burden due in part to the presence of the Anopheles gambiaecomplex.Among the eight sibling species An. gambiaes.s. and An. arabiensis are the two most important, efficient and widely distributed malaria vectors in Sub-Saharan Africa ${ }^{[4]}$ Similar scenario plays out in Nigeria with these two major malaria vectors spread across the country's ecological zones ${ }^{[5]}$. Robust evidence abound of incipient speciation in Anopheles gambiae complex ${ }^{[6]}{ }^{[7]}[8]\left[{ }^{[9]}[10]{ }^{[11]}\right.$. There are discrete subpopulations of An.gambiaes.s that are referred to as chromosomal form and molecular form. Individuals carrying the $\mathrm{C} / \mathrm{C}$ genotype are referred to as $\mathrm{M}$ molecular form,those carrying the $\mathrm{T} / \mathrm{T}$ genotype are known as $\mathrm{S}$ molecular forms ${ }^{[12]}$. These molecular forms are characterized based on either internal transcribed spacer (ITS) of the X-linked rDNA or intergenic spacer (IGS) using the distinct sequences observed in the established variants ${ }^{[13]}$. Both molecular forms are known to occur throughout Nigeria ${ }^{[14]}$.Since it is practically impossible, for now,to morphologically distinguish between the species in the Anopheles gambiae complex, several techniques have been employed over the years for their recognition. These methods range from cytogenetics ${ }^{[15] ~[16]}$, analysis of cuticular components ${ }^{[17]}{ }^{[18]}$ and now to the explosivemolecular methods which are excellent for detecting cryptic species. In this study molecular assay has been used to avoid misidentification between malaria vectors and non-vectors to authenticate their epidemiological roles for effective vectorcontrol.

\subsection{Study Area}

\section{Materials And Methods}

Thirteen communities in both Gboko and Otukpo local government areas of Benue State, North Central Nigeria were selected for the study. Seven of the study communities were rural and the inhabitants subsistence farmers while six were classified urbanwhere the inhabitants engage more in secondary economic activities. Based on Koppen climate classification, Benue State lies within the AW (tropical wet \& dry) climateand experiences two distinct seasons, the Wet season and the Dry season. The wet-rainy season lasts from April to 
October with annual rainfall in the range of $100-200 \mathrm{~mm}$. The dry season begins in November and ends in March.Temperatures fluctuate between 21 - 37 degrees Celsius in the year.The rural dwellings are traditional ancient mud huts, some partially plastered with cement and roofed with thatched dry grass or zinc. The urban dwellings are constructed of local mud burnt bricks or cement blocks and roofed with zinc, or long span aluminum sheets. In all the study communities several domestic animals such as goats, chicken, sheep, dogs, and pigs were sheltered in nearby pens at night but roamed about freely during the day. Some communities had even monkeys not too far from their bedrooms.

\subsection{Specimen Collection and Preservation.}

Indoor resting mosquitoes were collected using the Pyrethrum Spray Catch (PSC) between the hours 06:00 and 09:00 am in the study communities. Individual samples were each preserved dry over silica gel in well labelled Eppendorf tubes $(1.5 \mathrm{ml})$ prior to identification. This was to ensure preservation of delicate significant features that would be needed for morphological identification in the laboratory. They were then hand carried to the molecular laboratory at the Nigerian Institute of Medical research, Yaba,Lagos, Nigeria.

\subsection{Morphological Identification of Anopheles Species in the study communities}

Morphological identification was carried out using a trinoculardissecting microscope (Amscope SZMT2/MU1000 10APTINA COLOR CMOS) with the aid of standard keys ${ }^{[4]}{ }^{[19]}{ }^{[20]}$. First, significant features were employed to distinguish the Culicines from the Anophelines.Further key feature such as pattern of scales on the wings, shape, banding pattern and sizes of palps, leg and abdomen segmentation (Plates 1a-e) was then used to identify Anopheles species.

\subsection{Molecular Identification of Anopheles Species in the study communities}

Molecular identification was done using the Deoxyribonucleic Acid Polymerase Chain Reaction (DNA-PCR). The method by Scott et al. ${ }^{[2]}$ was used with slight modification in the extraction protocol. Further molecular analysis was done to determine the molecular forms of Anopheles gambiaes.s. ${ }^{[21]}$ using the Polymerase Chain-Restriction Fragment Length Polymorphism (PCR-RFLP) and the enzyme Hha1.

During this study the Molecular Entomology Laboratory, Public Health Division of the Nigerian Institute of Medical Research, Yaba, Lagos provided standard DNA obtained from known specimens that we used as our positive controls.Anopheles gambiaeKisumu laboratory strain were also used as positive control. Standard100bp DNA Ladder (Solis Biodyne-Estonia, Promega- GE Healthcare Bio-sciences USA) used, confirmed the sizes of the amplified products.

\subsection{Data analysis}

Data obtained was analysed using paired t-test and chi square to determine significant differences in species composition with SPSS version 22 and 23 and R Console software version 3.2.2.

\subsection{Mosquito Species Captured in the Study Communities}

\section{Results}

Composition and abundance of mosquito species in Gboko and Otukpo Local Government Area, Benue Sate, shows that a significant difference in composition/abundance was observed at $(\mathrm{p}<0.05)$. A total of one thousand seven hundred and thirty-four $(1,734)$ mosquitoes were recorded of whichCulex peaked 1,410 (81.31\%), Anopheles 276 (15.92\%) Mansoni 14(0.81\%), Aedeswas the least with a composition of only3 $(0.17 \%)$ and unidentified accounted for $31(1.79 \%)$ as shown in Table 1.

Table 1.Composition and Abundance of Mosquito Species in Gboko and Otukpo Local Government Areas, Benue State, North Central Nigeria in 2015.

\begin{tabular}{|l|l|l|}
\hline & $\mathrm{N}=1734$ & \\
\hline Mosquito Species & No. Observed & Composition/Abundance (\%) \\
\hline Culex & 1410 & 81.31 \\
\hline Anopheles gambiaes.1 & 276 & 15.92 \\
\hline Others & 31 & 1.79 \\
\hline Mansoni & 14 & 0.81 \\
\hline Aedes & 3 & 0.17 \\
\hline TOTAL & 1734 & 100 \\
\hline$\chi^{2}=73.65$ & $\mathrm{df}=4$ & $\mathrm{P}=0.001$ \\
\hline
\end{tabular}




\subsection{Morphological Identification of Anopheles Species and Composition in the Study Communities}

A total of two hundred and seventy-six (276) Anopheles mosquitoes were morphologically identified

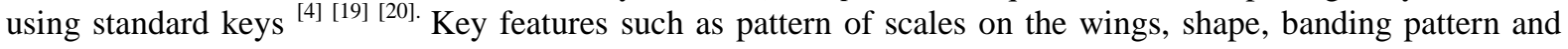
sizes of palps, leg and abdomen segmentation (Plates 1a-e) were also employed forAnopheles species authentication.

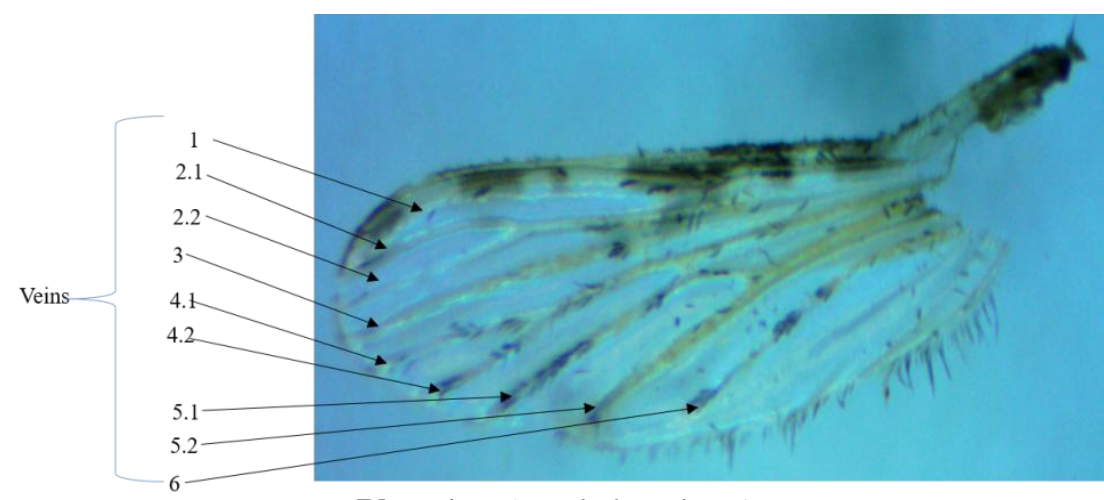

Plate 1a. Anopheles wing-1

Anopheles wing-1, showing pale scales creamy yellow, pale patches on costa and vein1, long fringe spot between vein 5.2 and 6.

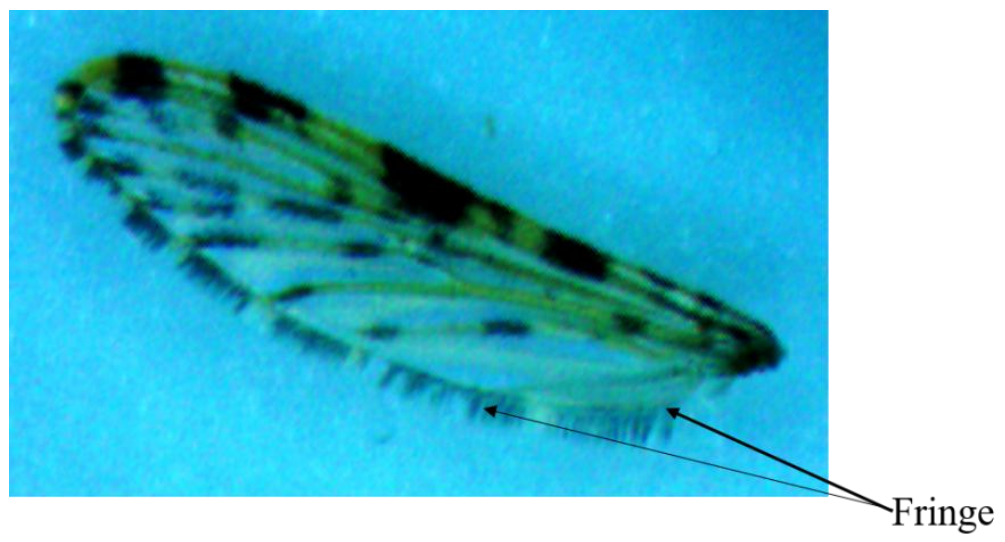

Plate:1b.Anopheles wing-2

Anopheles wing-2, showing dark and pale scales arranged in 'blocks'

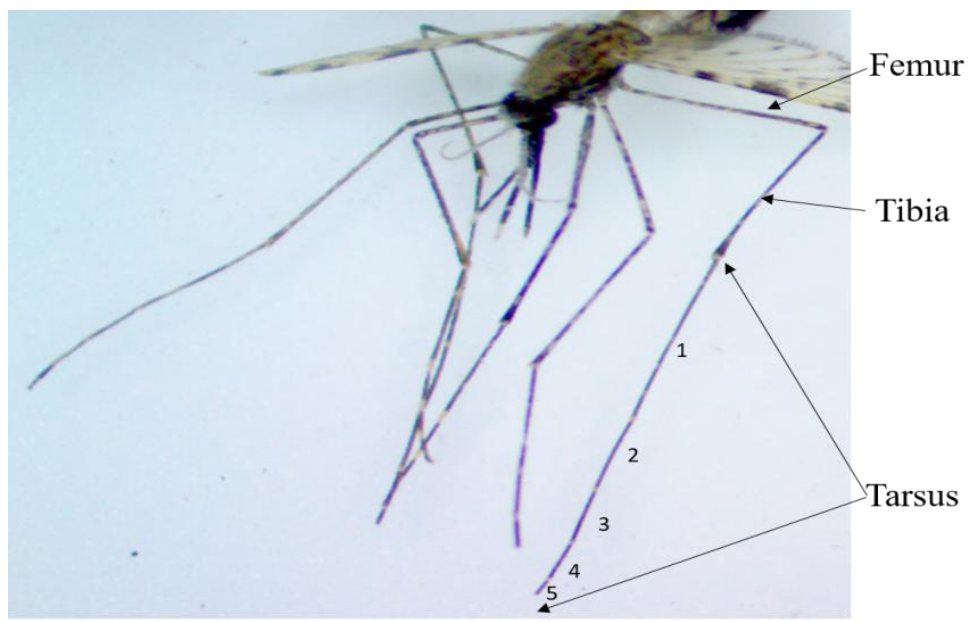

Plate 1c.Anopheles legs

Hind leg showing irregularly speckled femur and tibia, first, second, third tasi with apical and basal bands, (1-3 conspicuous and 4-5 just visible) NOTE: Proboscis as long as palps. 


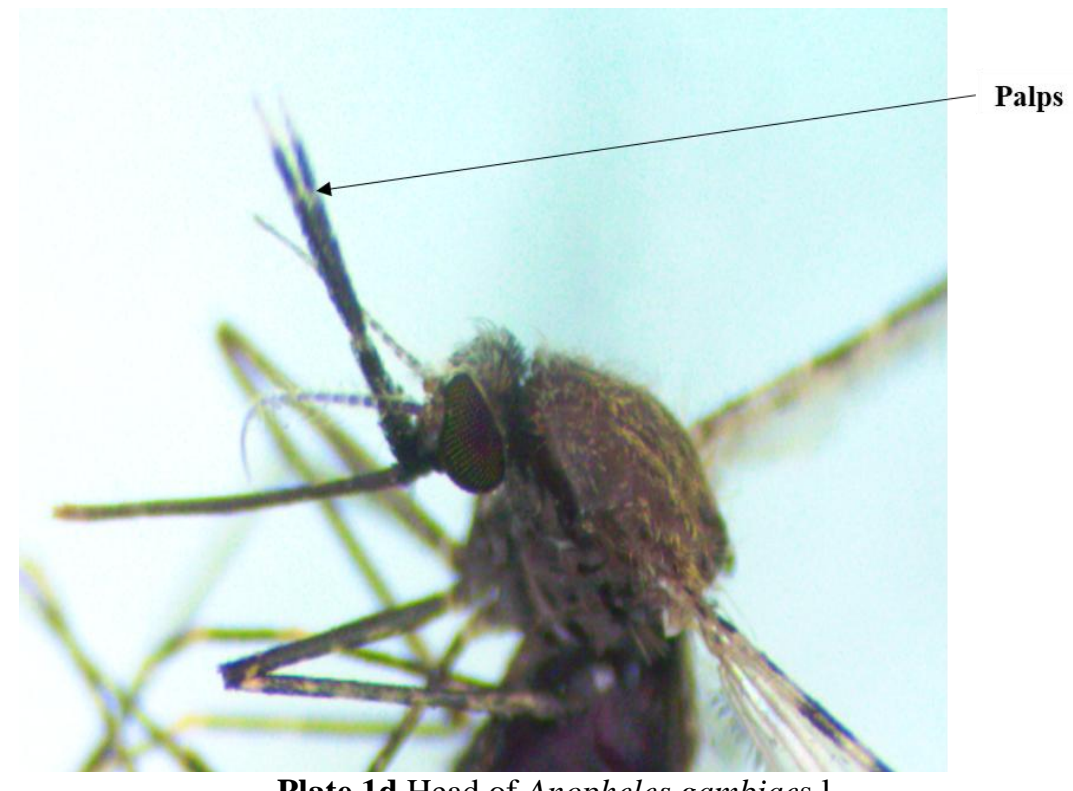

Plate 1d.Head of Anopheles gambiaes.1

Head of Anopheles gambiaes.lshowing Palps smooth with three bands/rings with apical bands interrupted or divided such that they look like four. NOTE: Proboscis as long as palps.

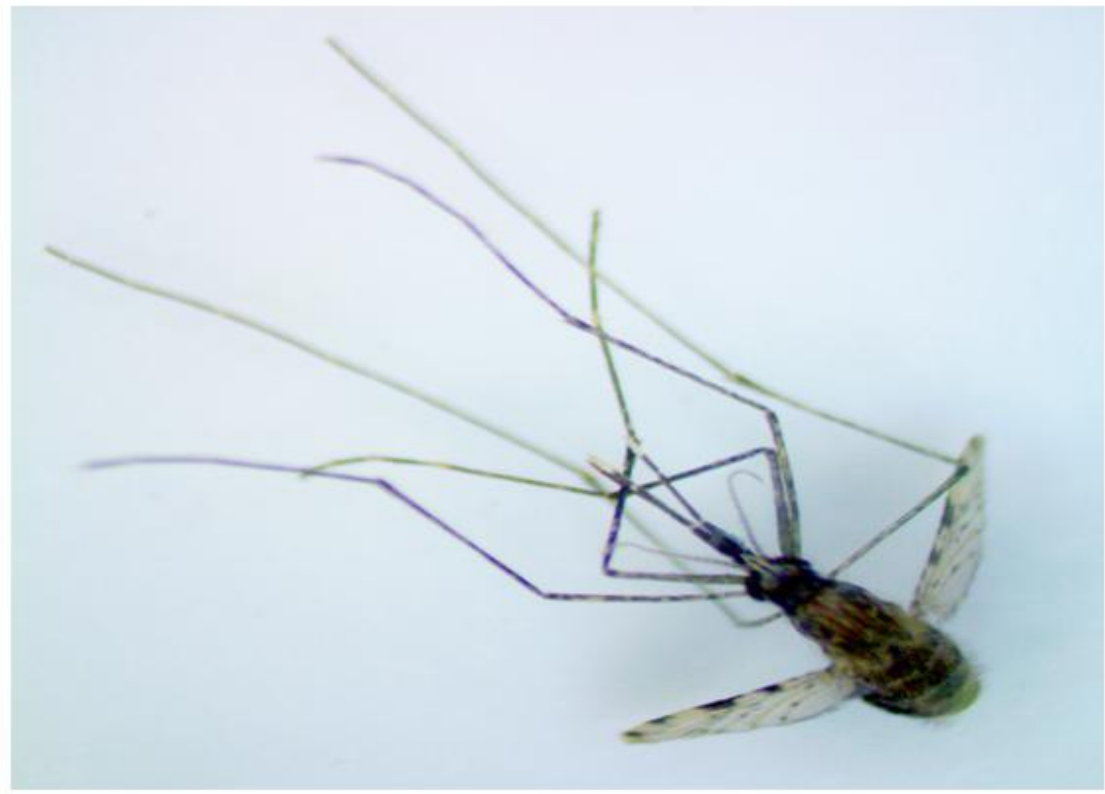

Plate 1e.Anopheles gambiaes.1

Anopheles gambiaes.lshowing abdomen and thorax clothed with yellowish scales and hair.

Anopheles species composition based on morphological identification (Table 2) in selected rural and urban communities from Gboko and Otukpo Local Government Area, Benue State, North Central Nigeria, shows that a significant difference $(\mathrm{p}=0.008)$ was observed in the Anopheles species composition within the communities at $(\mathrm{p}<0.05)$.Chember-Ipava rural community in Gboko had the highest composition with an abundance of 65(23.6\%) followed by Olahimu a rural community in Otukpo with 63(22.9\%) while the least was observed in Sabon-gari an urban community in Otukpo with an abundance of 1(0.4\%),no Anopheles species were recovered from Mkar in (Gboko) and Otobi in (Otukpo)urban and rural communities respectively. With respect to Urban-rural Anopheles species composition andabundance,rural communities had a significantly higher abundance of 262(95.3\%) compared to the urban communities with abundance of 13(4.7\%). 
Molecular Identification, Species Composition and Distribution Maps of Malaria Vector Species in ..

Table 2: Anopheles species composition based on morphological identification in selected rural and urban Communities from Gboko and Otukpo Local Government Areas, Benue State, North Central Nigeria in 2015.

\begin{tabular}{|c|c|c|c|}
\hline \multirow{3}{*}{ Location Index } & \multirow[b]{3}{*}{ Communities } & \multicolumn{2}{|l|}{$\mathrm{N}=275$} \\
\hline & & & \\
\hline & & LGA & Abundance (\%) \\
\hline & Chember-Ipav & Gboko & $65(23.6)$ \\
\hline & Olahimu & Otukpo & $63(22.9)$ \\
\hline & Vende & Gboko & $53(19.3)$ \\
\hline \multirow[t]{7}{*}{ Rural } & Yiase & Gboko & $43(15.6)$ \\
\hline & Otada & Otukpo & $35(12.7)$ \\
\hline & Otukpo-Icho & Otukpo & $3(1.1)$ \\
\hline & Otobi & Otukpo & $0(0)$ \\
\hline & Sub-Total & & $262(95.3)$ \\
\hline & Genyi & Gboko & $4(1.5)$ \\
\hline & Babylon & Otukpo & $4(1.5)$ \\
\hline \multirow[t]{7}{*}{ Urban } & GRA-Gboko & Gboko & $2(0.7)$ \\
\hline & GRA-Otukpo & Otukpo & $2(0.7)$ \\
\hline & Sabon-gari & Otukpo & $1(0.4)$ \\
\hline & Mkar & Gboko & $0(0)$ \\
\hline & Sub-Total & & $13(4.7)$ \\
\hline & Grand-Total & & $275(100.0)$ \\
\hline & $\chi^{2}=54.65$ & $\mathrm{df}=12$ & $\mathrm{p}=0.008$ \\
\hline
\end{tabular}

\subsection{Molecular Identification of Anopheles Species in the Study Communities.}

Malaria vector species composition in the selected communities based on molecular identification in Gboko and Otukpo Local Government Area, Benue State in 2015 (Table 3), shows a significant difference $(\mathrm{p}=0.015)$ in the vector composition in the selected communities in Gboko and Otukpo observed at $(\mathrm{p}<0.05)$. Chember-Ipav (Gboko) a rural community had the highest composition of 35 vectors of which all 35(100.0\%) were An. gambiae followed by Vende(Gboko) another rural community with 32 vectors of which 31(96.9\%) wereAn. gambiae and 1(3.1\%) was An. Arabiensis. The least was observed in Genyi(Gboko), Babylon(Otukpo), GRA-Gboko and GRA-Otukpo all urban communities with vector composition of 1 respectively, all presence of single vector observed in these communities were An. gambiae 1(100.0\%) respectively. No vector was observed in Otukpo-Icho (Otukpo) and Otobi(Otukpo) both rural communites and Sabongari (Otukpo) and Mkar (Gboko) urban communities. Of the 133 vectors observed, An. gambiae had a higher composition $129(97.0 \%)$ compared to An.arabiensis 4(3.0\%) while with respect to An. arabiensis rural had the highest composition $4(3.1 \%)$ compared to urban $0(0 \%)$ as shown in Table 3 below.

Table 3. Malaria Vector Species Composition based on molecular identification in the Selected Communities in Gboko and Otukpo Local Government Areas of Benue State, North Central Nigeria in 2015.

\begin{tabular}{|c|c|c|c|c|c|}
\hline & & \multicolumn{4}{|c|}{$\mathrm{N}=133$} \\
\hline \multirow[t]{4}{*}{ Location Index } & Community & LGA & No. Of vectors & An. gambiae $(\%)$ & An. Arabiensis (\%) \\
\hline & Chember-Ipav & Gboko & 35 & $35(100.0)$ & $0(0)$ \\
\hline & Vende & Gboko & 32 & $31(96.9)$ & $1(3.1)$ \\
\hline & Olahimu & Otukpo & 27 & $27(100.0)$ & $0(0)$ \\
\hline \multirow[t]{7}{*}{ Rural } & Yiase & Gboko & 18 & $16(88.9)$ & $2(11.1)$ \\
\hline & Otada & Otukpo & 17 & $16(94.1)$ & $1(5.9)$ \\
\hline & Otukpo-Icho & Otukpo & 0 & $0(0)$ & $0(0)$ \\
\hline & Otobi & Otukpo & 0 & $0(0)$ & $0(0)$ \\
\hline & Sub-Total & & 129 & 125(96.9) & $4(3.1)$ \\
\hline & Genyi & Gboko & 1 & $1(100.0)$ & $0(0)$ \\
\hline & Babylon & Otukpo & 1 & $1(100.0)$ & $0(0)$ \\
\hline \multirow[t]{7}{*}{ Urban } & GRA-Gboko & Gboko & 1 & $1(100.0)$ & $0(0)$ \\
\hline & GRA-Otukpo & Otukpo & 1 & $1(100.0)$ & $0(0)$ \\
\hline & Sabon-gari & Otukpo & 0 & $0(0)$ & $0(0)$ \\
\hline & Mkar & Gboko & 0 & $0(0)$ & $0(0)$ \\
\hline & Sub-Total & & 4 & $4(100.0)$ & $\mathbf{0}(\mathbf{0})$ \\
\hline & Grand-Total & & 133 & $129(97.0)$ & $4(3.0)$ \\
\hline & $\chi^{2}=25.15$ & \multicolumn{2}{|c|}{$\mathrm{df}=12$} & & $\mathrm{p}=0.015$ \\
\hline
\end{tabular}

The PCR assay revealed An.gambiaes.s. and An.arabiensis( Plate 1\& 2 ) as the Anopheles vector species present in the study communities withAnopheles gambiaes.s having a much higher density than Anopheles arabiensis(Table 3).The PCR-RFLP showed all three forms (M,S,H) forms of Anopheles gambiaes.s 
(Plate 3). A total of one hundred and forty-one were successfully assayed of which thirty (30) were M-form, eighty-eight (88) were S-form, three (3) were $\mathrm{H}$ form while twenty (20) did not amplify as shown in Fig. 1.

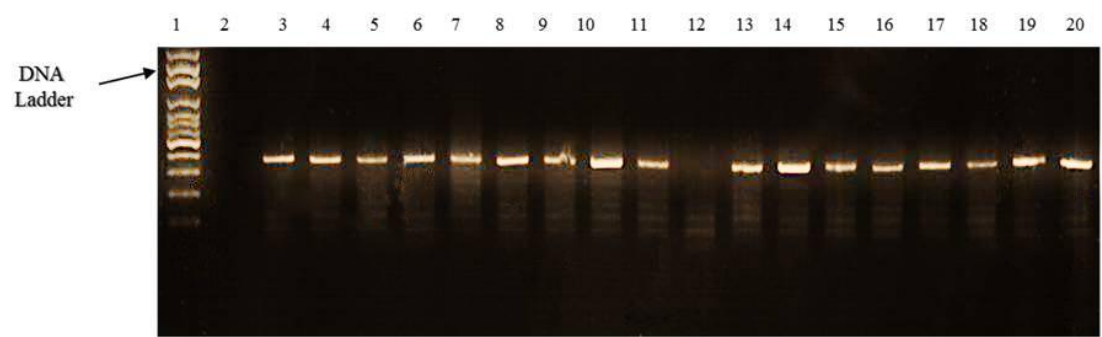

Plate 1:PCR Amplification of Anopheles gambiaes.l.

Lane 1 = DNA ladder, Lane $2=$ Negative control. Lane $3=$ An. gambiaepositive control .

Lane $4-20=$ Samples analyzed

Lane 12=NA-not amplified

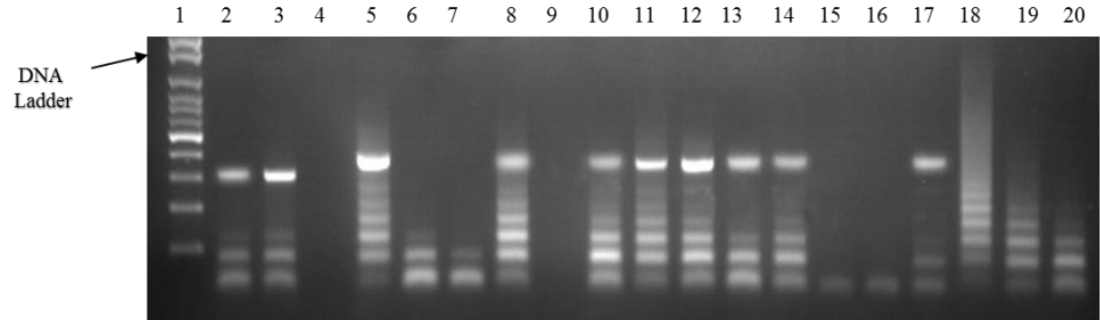

Plate 2:PCR Amplification of Anopheles gambiaes.l.

Lane 1 = DNA ladder, Lane 2= positive control - An.arabiensis.

Lane $3=$ An.arabiensisLane 5,10,11,12,13,14 = An.gambiaes.s.

Lanes $=4,6,7,9,15,16,18,19,20=$ NA-not amplified

$\begin{array}{llllllllllllllllllll}1 & 2 & 3 & 4 & 5 & 6 & 7 & 8 & 9 & 10 & 11 & 12 & 13 & 14 & 15 & 16 & 17 & 18 & 19 & 20\end{array}$

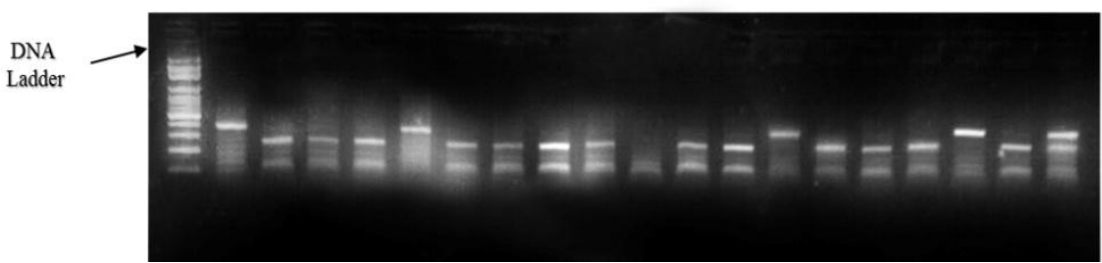

Plate 3: Enzyme Digestion of An. gambiaes.s.using Hha1.

Lane 1 = DNA ladder. Lanes 3,4,5,7,8,9,10,12,13,15,16,17,19=S-forms

Lanes 2,6,14, \& 18=M-forms. Lane $20=\mathrm{H}$-form

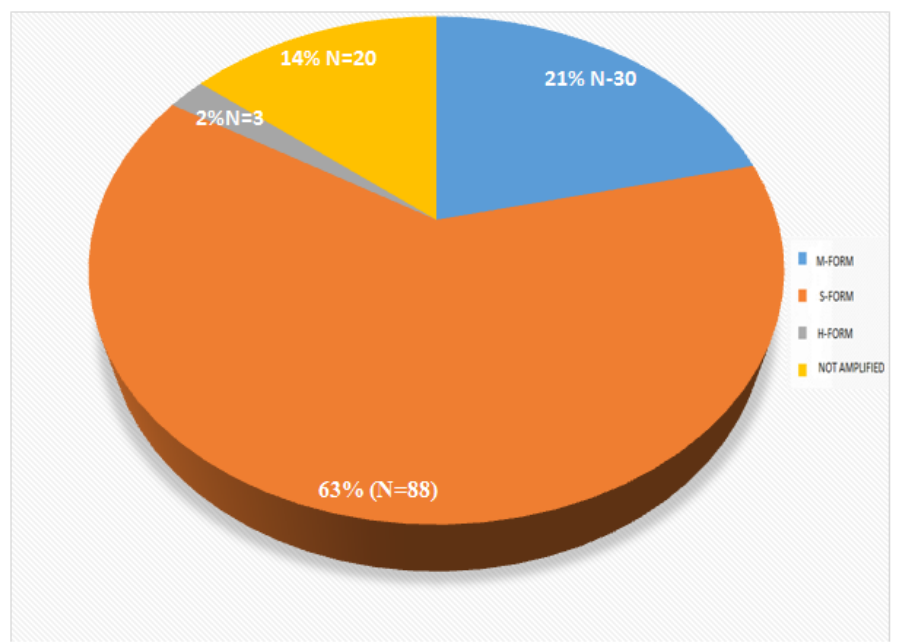


Figure 1: Molecular Forms of An. gambiaes.s

\subsection{Distribution Maps of Malaria Vector Species in Selected Communities}

The geographic distribution of the identified members of the An. gambiae complex Fig. 2 and 3 in the study communities show their existence, location and occurrence in sympatry. The National Centre for Remote Sensing (NCRS) helped to generate the map using the results from the investigation to show the distribution of the various malaria vector species captured in the selected communities.

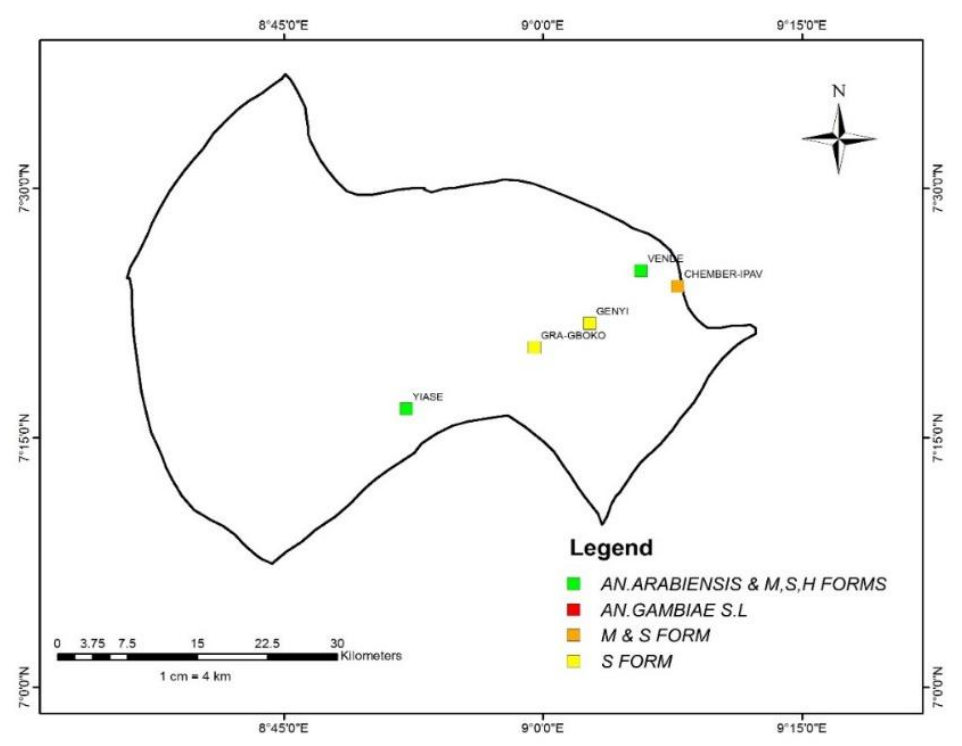

Figure 2. Map of Gboko Local Government Area Showing Malaria Vector Distribution

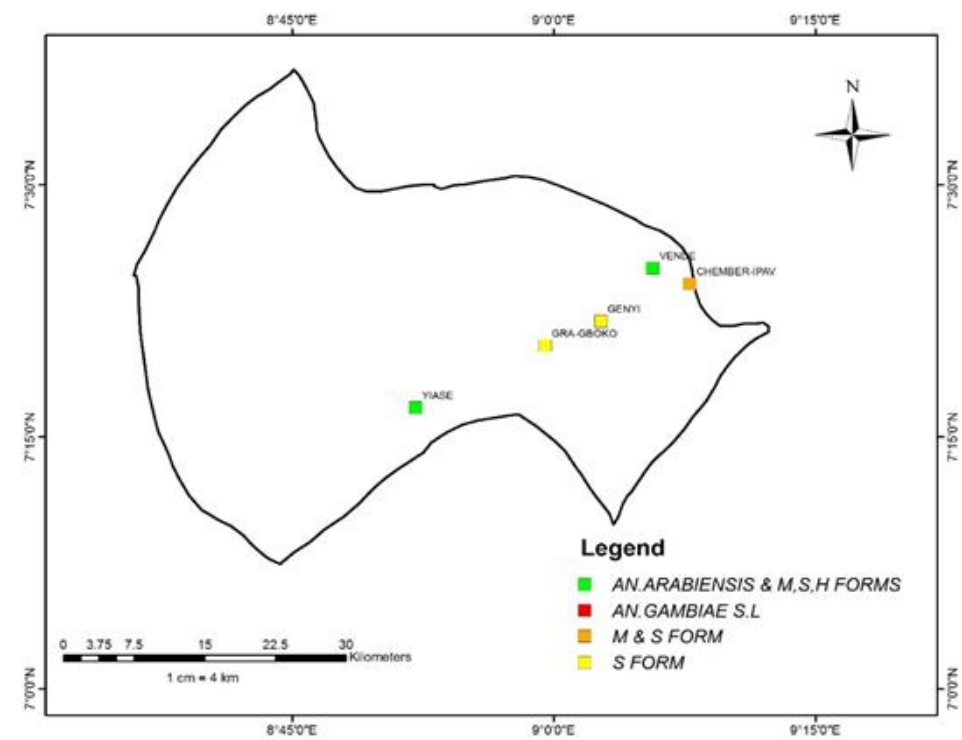

Figure 3.Map of Otukpo Local Government Area Showing Malaria Vector Distribution

\section{Discussion}

Some members of the Anopheles gambiae complex enjoy a wide distribution and attention as one of the most efficient malaria vectors in Sub Saharan Africa.Two of the sibling species An.gambiaes.s and An. arabiensisare of the greatest medical importance in Nigeria ${ }^{[8]}$. Onyabe and conn in $2001^{[7]}$ disclosed that each of these two species were prevalent over the other in at least one locality in each of the five ecological zones of Nigeria and both species coexisted in several localities but in very disproportional numbers. On the distribution of the molecular forms across Nigeria,Onyabe and co-authors in $2003^{[14]}$ reported both $\mathrm{S}$ and $\mathrm{M}$ forms occurred across Nigeria with no apparent relationship to the ecological transition from the savannah to forest zones, and also stated that no hybrids between the two forms were detected. Okorie and co-authors in 2011 also reported on the distribution of $\mathrm{M}$ and $\mathrm{S}$ forms in the different ecological zones, but no mention of the hybrid form. In 
agreement with the above reports, results of this investigation also found these malaria vector species existing in sympatry.The findings from this research reveal for the first timethe detection of the hybrid forms in these study communities. The continuous generation of malaria vector distributional data and maps serve as a useful tool for malaria risk indices stratification and provides information for presence or absence of malaria vectors from nonvectors which are central for planning malaria control programmes. Sinceour observations are the first from these study communities they serve as baseline data for future work in a manner after a series of work ${ }^{[22] ~[23] ~}$ ${ }^{[24]}$ done in the south western part of Nigeria. This study has provided valuable and complimentary information to the national malaria database. Based on molecular and bionomical evidence, the An. gambiae molecular "M form" is named Anopheles coluzzii Coetzee \&Wilkerson sp. n., while the "S form" retains the nominotypical name Anopheles gambiae Giles. Anopheles quadriannulatus is retained for the southern African populations of this species, while the Ethiopian species is named Anopheles amharicus Hunt, Wilkerson \& Coetzee sp. n.,based on chromosomal, cross-mating and molecular evidence ${ }^{[25]}$.

\section{Conclusion}

Inaccurate identification of vector species lead to ineffective control strategies which can now be avoided in these communities using these key information as baseline data for planning effective malaria control programmes. The detection of hybrid forms calls for further investigation into the population genetic structure of the molecular forms in these communities.

\section{References}

[1] M.Service, A guide to medical entomology for students(New York: CambridgeUniversity Press, 2013).

[2] J.A. Scott, W.G. Brogdon, and F.H. Collins, Identification of single specimens of the Anopheles gambiae complex by the polymerase chain reaction, American Journal of Tropical Medicine and Hygiene, 49, 1993, 520-529.

[3] M. E.Sinka, M. J. Bangs, S.Manguin, M. Coetzee, C. M.Mbogo, J. Hemingway, and R. M. Okara,The dominant Anopheles vectors of human malaria in Africa, Europe and the Middle East: occurrence data, distribution maps and bionomic précis. Parasites \& vectors, 3(1), 2010, 1

[4] M. T. Gillies, and M. Coetzee,A Supplement to the Anophelinae of Africa South of the Sahara. Publication of the South African Institute for Medical Research, 55, 1987Anopheles gambiae and Anopheles arabiensis, in Nigeria. Memórias do Instituto Oswaldo Cruz, 96(8), 2001, 1081-1084.

[5] G. Davidson, and C. E. Jackson, Incipient speciation in Anopheles gambiae Giles. Bulletin of the World Health Organization, 27(2), $1962,303$.

[6] G. B. White, Anopheles gambiae complex and disease transmission in Africa. Transactions of the Royal Society of Tropical Medicine and hygiene, 68(4), 1974, 278-298., 1-143.

[7] D. Y.Onyabe, and J. E. Conn, The distribution of two major malaria vectors, Anopheles gambiae and Anopheles arabiensis, in Nigeria. Memórias do Instituto Oswaldo Cruz. 2001 Nov;96(8):1081-4.

[8] M.Coluzzi, A. Sabatini, V.Petrarca, and M.A. Di Deco, Chromosomal differentiation and adaptation to human environments in the Anopheles gambiae complex. Transactions of the Royal Society of Tropical Medicine and Hygiene,73(5), 1979, 483-97.

[9] A. D. Torre, C.Fanello, M.Akogbeto, J.Dossou- yovo, G.Favia, V.Petrarca, and M. Coluzzi, Molecular evidence of incipient speciation within Anopheles gambiaess in West Africa. Insect molecular biology, 10(1),2001, 9-18.

[10] M.Pombi, B. Caputo, F. Simard, M. A. Di Deco, M.Coluzzi,A. Della Torre, V. Petrarca, Chromosomal plasticity and evolutionary potential in the malaria vector Anopheles gambiaesensustricto: insights from three decades of rare paracentric inversions. Evolutionary Biology 8, 2008,309,htt//doi:10.1186/1471-2148-8-309

[11] M. K. Lawniczak, S. J.Emrich, A. K. Holloway, A. P.Regier, M. Olson, B. White, and C. Farmer, Widespread divergence between incipient Anopheles gambiae species revealed by whole genome sequences. Science, 330(6003),2010, 512-514.

[12] G. C.Lanzaro, and Y. Lee, Speciation in Anopheles gambiae. The distribution of genetic polymorphism and patterns of reproductive isolation among natural populations. Anopheles mosquitoes-New insights into malaria vectors. InTech, 2013.

[13] G. Gentile, A. Della Torre, B.Maegga, J. R. Powell, and A. Caccone, Genetic differentiation in the African malaria vector, Anopheles gambiaess, and the problem of taxonomic status. Genetics, 161(4), 2002,1561-1578.

[14] D. Y.Onyabe, C. G.Vajime, I. H. Nock, I. S.Ndams, A. U.Akpa, A. A.Alaribe, and J. E. Conn, The distribution of M and S molecular forms of Anopheles gambiae in Nigeria. Transactions of the Royal Society of Tropical Medicine and Hygiene, 97(5),2003, 605-608.

[15] J. B. Kitzmiller, Mosquito cytogenetics: A Review of the literature, 1953-62. Bulletin of the World Health Organization, 29(3), $1963,345$.

[16] M.Coluzzi, A. Sabatini, A.della Torre, M. A. Di Deco, and V. Petrarca, A polytene chromosome analysis of the Anopheles gambiaespecies complex. Science, 298 (5597), 2002, 1415-1418.

[17] G. I.Anyanwu, D. H.Molyneux, and A. Phillips, Variation in cuticular hydrocarbons among strains of the Anopheles gambiaesensustricto by analysis of cuticular hydrocarbons using gas liquid chromatography of larvae. Memórias do Instituto Oswaldo Cruz, 95(3), 2000, 295-300.

[18] D. A. Carlson, Identification of mosquitoes of Anopheles gambiae species complex A and B by analysis of cuticular components, 1980 .

[19] J. D. Gillett, Common African mosquitos and their medical importance (London William Heinemann, 1972).

[20] M. T. Gillies, and B. De Meillon, The anophelinae of Africa south of the Sahara (Ethiopian zoogeographical region). The Anophelinae of Africa south of the Sahara (Ethiopian Zoogeographical Region), 1968.

[21] G.Favia, A. Della Torre, M.Bagayoko, A.Lanfrancotti, N. F.Sagnon, Y. T.Touré, and M. Coluzzi, Molecular identification of sympatric chromosomal forms of Anopheles gambiae and further evidence of their reproductive isolation. Insect molecular biology, 6(4),(1997). 377-383.

[22] T. S. Awolola, K. Ibrahim, T.Okorie, L. L.Koekemoer, R. H. Hunt, and M. Coetzee, Species composition and biting activities of anthropophilicAnopheles mosquitoes and their role in malaria transmission in a holo-endemic area of southwestern Nigeria. African entomology, 11(2), (2003). 227-232. 
[23] T.S.Awolola, I.O.Oyewole, C.N.Amajoh, E.T.Idowu, M.B.Ajayi, A.Oduola, O.U.Manafa, K. Ibrahim, L.L.Koekemoer, M. Coetzee, Distribution of the molecular forms of Anopheles gambiae and pyrethroid knock down resistance gene in Nigeria. Actatropica, 95(3), 2005, 204-209.

[24] I.O.Oyewole, A.Ibidapo, A.O.Oduola, J.B.Obansa, and T.S. Awolola, Molecular identification and population dynamics of the major malaria vectors in a rainforest zone of Nigeria. Biokemistri 17, 2005, 171-178.

[25] M. Coetzee, R. H. Hunt, R. Wilkerson, A. Della Torre, M. B.Coulibaly and N. J. Besansky, Anopheles coluzzii and Anopheles amharicus, new members of the Anopheles gambiae complex. Zootaxa, 3619(3),2013, 246-274. 